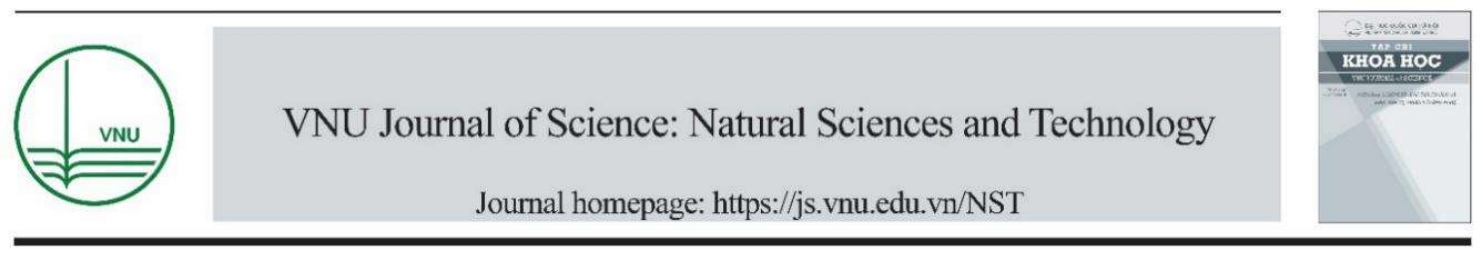

Original Article

\title{
Synthesis and Spectroscopic Characterizations of Ni(II) Thiosemicarbazone Bearing Anthracene
}

\author{
Dinh Thi Hien ${ }^{1}$, Khuat Thi Thuy $\mathrm{Ha}^{2}$, Vu Thi Bich Ngoc ${ }^{2}$, Nguyen Tien Dat ${ }^{2}$, \\ Dinh Thi Thao ${ }^{3}$, Nguyen Minh Hai ${ }^{2}$,* \\ ${ }^{1}$ Hanoi National University of Education, 136 Xuan Thuy, Cau Giay, Hanoi, Vietnam \\ ${ }^{2}$ VNU University of Science, 19 Le Thanh Tong, Hoan Kiem, Hanoi, Vietnam \\ ${ }^{3}$ Army Academy 1, Co Dong, Son Tay, Hanoi, Vietnam
}

Received 29 October 2020

Revised xxx 2021; Accepted xxx 2021

\begin{abstract}
The X-ray structure of 9-anthraldehyde-4-methyl-3-thiosemicarbazone was firstly determined. The Ni(II) complex with this ligand was prepared upon reaction with chloride salt. Mass spectrometry result confirms correct formulation of the complex. Unusual ${ }^{1} \mathrm{H}$ NMR signal pattern of anthracene moiety reveal cis arrangement cemented by intramolecular $\pi-\pi$ stackings between aromatic rings. As a result of this interaction, the electronic structure of anthracene ring is perturbed and gives rise to structureless and broad absorption and emission bands.
\end{abstract}

Keywords: Anthracene, thiosemicarbazone, nickel, spectroscopies, $\pi-\pi$ interactions.

\section{Introduction}

Having a large $\pi$ system, anthracene has been found useful in many areas such as structural chemistry and fluorescent sensing [1, 2]. In close proximity with parallel arrangement, two anthracene rings are able to give excimer emission with green or greenish yellow color [3]. In order to bring forth this intriguing property, it is important to design a linker that might put the two aromatic rings in such arrangement.
Thiosemicarbazone is a well-known class of ligands that may give rise to unexpected coordination chemistry. $\mathrm{Ni}(\mathrm{II})$, a $d^{8}$ metal, tends to form square planar geometries with trans configuration which is more favorable in energy. Nonetheless, many $\mathrm{Ni}(\mathrm{II})$ thiosemicarbazone complexes with cis geometries were reported. Indeed, weak interactions such as $\pi-\pi$ stackings among the thiosemicarbazone ligands are needed to sustain the cis arrangements [4, 5]. Our group also reported anthracene-based and pyrenebased $\mathrm{Ni}(\mathrm{II})$ thiosemicarbazone complexes

\footnotetext{
${ }^{*}$ Corresponding author.

Email address: minhhai.nguyen@hus.edu.vn.
}

https://doi.org/10.25073/2588-1140/vnunst.5152 
which showed cis geometries cemented by intramolecular $\pi-\pi$ interactions $[6,7]$. In this paper, a new Ni(II) complex with anthracenebased thiosemicarbazone (NiL) is presented. Spectroscopic data such as ${ }^{1} \mathrm{H}-\mathrm{NMR}$, electronic absorption and emission support cis square planar structure around $\mathrm{Ni}(\mathrm{II})$ ion.

\section{Experimental}

\subsection{Materials and Instruments}

All the solvents used for synthesis and spectroscopic measurements were purified according to literature procedures. 9Anthraldehyde and 4-methyl-3thiosemicarbazide were used as received without further purification.

The FT-IR spectra of the compounds were measured on a FT-IR 8700 infrared spectrophotometer $\left(4000-400 \mathrm{~cm}^{-1}\right)$ in $\mathrm{KBr}$ pellets. The ${ }^{1} \mathrm{H}$ NMR spectra were recorded on an AVANCE Bruker-500MHz spectrometer in DMSO- $d_{6}$ solution at room temperature. ESIMS spectra were recorded on an Agilent LC/MSD SL spectrometer.

Absorption and emission spectra of the complexes were measured in dichloromethane at room temperature on Jasco UV-Vis spectrometer and Hitachi fluorescence spectrophotometer.

The intensities for the X-ray determinations were collected on a Bruker D8 Quest instrument with Mo K $\alpha$ radiation $(\lambda=0.71073 \AA)$. Standard procedures were applied for data reduction and absorption correction. Structure solution and refinement were performed with OLEX2 and SHELXT programs [8, 9]. Hydrogen atom positions were calculated for idealized positions.

The synthesis of HL has been reported elsewhere [10].

\subsection{Synthesis of $\boldsymbol{H L}$}

To a $10 \mathrm{~mL}$ ethanolic solution of 9anthraldehyde $(0.206 \mathrm{~g}, 1.0 \mathrm{mmol})$ was added 10 $\mathrm{mL}$ acidified aqueous solution of 4-methyl-3thiosemicarbazide $(0.105 \mathrm{~g}, 1.0 \mathrm{mmol})$. The resulting mixture was stirred for $4 \mathrm{~h}$ at $60^{\circ} \mathrm{C}$ to afford a pale yellow solid. The product was washed by a large amount of water and then airdried. Yield: $0.228 \mathrm{~g}, 78 \%$.

Spectroscopic Data for HL. IR: $v_{\max } / \mathrm{cm}^{-1}=$ 3399 (m), 3216 (m), 3062 (w), 2926 (w), 1523 (s), 1436 (m), 1204 (s), 1077 (w), 890 (w), 732 (m), 607 (w). ${ }^{1} \mathbf{H}$ NMR (DMSO-d $d_{6}$ ): 11.67 (s, $\left.1 \mathrm{H}, \mathrm{N}^{(2)} \mathrm{H}\right), 9.27(\mathrm{~s}, 1 \mathrm{H}, \mathrm{CH}=\mathrm{N}), 8.70(\mathrm{~s}, 1 \mathrm{H}$, $\left.\mathrm{H}_{10}\right), 8.49\left(\mathrm{~d}, 2 \mathrm{H}, \mathrm{H}_{1,8}\right), 8.32\left(\mathrm{q}, 1 \mathrm{H}, \mathrm{N}^{(4)} \mathrm{H}\right), 8.14$ $\left(\mathrm{d}, 2 \mathrm{H}, \mathrm{H}_{4,5}\right), 7.65-7.56\left(\mathrm{~m}, 4 \mathrm{H}, \mathrm{H}_{2,3,6,7}\right), 3.01$ (d, $3 \mathrm{H}, \mathrm{CH}_{3}$ ).

Crystal Data for HL: orthorhombic, space group Pna2 $2_{1}$ (no. 33), $a=16.7442$ (14) $\AA, b=$ 15.8556(10) $\AA, c=\quad$ 5.2324(4) $\AA, V=$ $1389.15(18) \AA^{3}, Z=4, T=0.0 \mathrm{~K}, \mu(\mathrm{MoK} \alpha)=$ $0.229 \quad \mathrm{~mm}^{-1}$, Dcalc $=1.403 \mathrm{~g} / \mathrm{cm}^{3}, \quad 3923$ reflections measured $\left(7.078^{\circ} \leq 2 \Theta \leq 56.448^{\circ}\right)$, 2203 unique $\left(R_{\text {int }}=0.0417, \mathrm{R}_{\text {sigma }}=0.0580\right)$ which were used in all calculations. The final $R_{1}$ was 0.0388 (I $>2 \sigma(\mathrm{I})$ ) and $w R_{2}$ was 0.0846 (all data).

\subsection{Synthesis of $\mathrm{NiL}$}

A solution of $\mathrm{NiCl}_{2}(0.009 \mathrm{~g}, 0.04 \mathrm{mmol})$ in acetone $(5 \mathrm{~mL})$ was added dropwise to a solution of $\mathbf{H L}(0.023 \mathrm{~g}, 0.08 \mathrm{mmol})$ in acetone $(15 \mathrm{~mL})$ in the presence of excess triethylamine. The mixture was heated to $60^{\circ} \mathrm{C}$ and stirred for $5 \mathrm{~h}$ in darkness, then filtered, washed with methanol, and lastly dried in vacuum to give dark-red product. Yield: $0.015 \mathrm{~g}, 58 \%$.

Spectroscopic Data for NiL. IR: $v_{\max } / \mathrm{cm}^{-1}$ $=3309(\mathrm{~s}), 3020(\mathrm{w}), 2833(\mathrm{w}), 1518(\mathrm{~s}), 1405$ (m), $1262(\mathrm{~m}), 1190(\mathrm{~m}), 887(\mathrm{w}), 739(\mathrm{~m}), 616$ (w). ${ }^{1} \mathbf{H}$ NMR (DMSO- $\left.d_{6}\right): 8.71\left(\mathrm{~s}, 2 \mathrm{H}, \mathrm{H}_{10}\right)$, $8.12\left(\mathrm{~m}, 4 \mathrm{H}, \mathrm{H}_{4,5}\right), 7.83(\mathrm{~s}, 2 \mathrm{H}, \mathrm{CH}=\mathrm{N}), 7.45(\mathrm{~m}$, $\left.4 \mathrm{H}, \mathrm{H}_{3,6}\right), 6.78$ (q, 2H, NH), $2.41\left(\mathrm{~d}, 6 \mathrm{H}, \mathrm{CH}_{3}\right)$. ESI-MS: $m / z$ 642.9, $[\mathrm{M}+\mathrm{H}]^{+}$.

\section{Results and Discussion}

\subsection{Synthesis}

The ligand HL was obtained from reaction between 9-anthraldehyde and acidified 4methyl-3-thiosemicarbazide using previously reported method [10]. The ligand was then 
allowed to react with $\mathrm{NiCl}_{2}$ in boiling acetone with the aid of an organic base (triethylamine), as shown in Scheme 1. The resulting complex NiL was separated in high yield as dark red solid. Notably, single crystals of HL could be collected from dichloromethane/methanol mixture, making its X-ray crystallography characterization feasible. Unfortunately, numerous attempts to obtain single crystals of NiL failed.<smiles>CNC(=S)N/N=C/c1c2ccccc2cc2ccccc12</smiles>

Scheme 1: Synthetic pathway of NiL.

Many physical methods such as infra-red spectroscopy, mass spectrometry (ESI-MS), and ${ }^{1} \mathrm{H}$ NMR spectroscopy were adopted to characterize the complex. ESI-MS result reveals major cluster peak responsible for molecular ion $[\mathrm{NiL}+\mathrm{H}]^{+}$at $\mathrm{m} / \mathrm{z}=643$ (Figure 1). The little discrepancy between theoretical and experimental isotopic patterns of the cluster peak help confirm the correct formulation of NiL with one central $\mathrm{Ni}(\mathrm{II})$ ion and two thiosemicarbazone ligands. The bathochromic shift of $v(\mathrm{C}=\mathrm{N})$ from $1523 \mathrm{~cm}^{-1}$ in $\mathbf{H L}$ to 1517 $\mathrm{cm}^{-1}$ in $\mathrm{NiL}$ in the IR spectra indicated the complexation through imine nitrogen of $\mathbf{H L}$. Moreover, the band due to $v(\mathrm{C}=\mathrm{S})$ at $890 \mathrm{~cm}^{-1}$ in $\mathbf{N i L}$ is shorter than that in $\mathbf{H L}$ by $3 \mathrm{~cm}^{-1}$. This is reasonable in light of the tautomerization of the ligands into thiol form in which $\mathrm{C}=\mathrm{S}$ bond is converted to $\mathrm{C}-\mathrm{S}$ and then $\mathrm{C}-\mathrm{S}-\mathrm{Ni}$ linkages upon complexation [11].

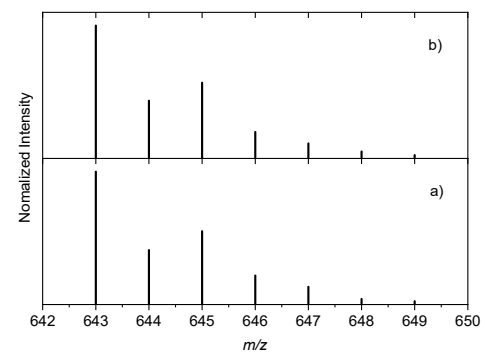

Figure 1: a) Simulated isotopic pattern for $[\mathbf{N i L}+$ $\mathrm{H}]^{+}$; b) ESI-MS cluster peak for $[\mathbf{N i L}+\mathrm{H}]^{+}$.

The ${ }^{1} \mathrm{H}$ NMR spectra of $\mathbf{H L}$ and NiL in DMSO- $d_{6}$ are given in Figure 2. It is reasonable to confirm square planar geometry of NiL given its sharp signals which are only possible for diamagnetic $\mathrm{Ni}(\mathrm{II})$ complexes. The $\mathrm{N}^{(2)}-\mathrm{H}$ signal (11.67 ppm) in $\mathbf{H L}$ are not found in the spectrum of NiL, hinting the tautomerization of the ligand upon complexation with $\mathrm{Ni}(\mathrm{II})$. Moreover, $\mathrm{N}^{(4)}$ substituted methyl groups in HL and NiL give rise to doublet signal at $3.02 \mathrm{ppm}$ and $2.41 \mathrm{ppm}$, respectively. A quartet at $6.78 \mathrm{ppm}$ arising from $\mathrm{N}^{(4)} \mathrm{H}$ in NiL is largely upfield shifted from that in HL (8.32 ppm).

Because of steric effect, mono-substituted anthracene ring is expected to show a typical set of proton signals including one singlet $\left(\mathrm{H}_{10}\right)$, two doublets $\left(\mathrm{H}_{1,8}\right.$ and $\left.\mathrm{H}_{4,5}\right)$, and two triplets $\left(\mathrm{H}_{2,3,6,7}\right)$. Unexpectedly, only three proton signals responsible for $\mathrm{H}_{10}(8.71 \mathrm{ppm}), \mathrm{H}_{4,5}(8.12 \mathrm{ppm})$, $\mathrm{H}_{3,6}(7.46 \mathrm{ppm})$ in anthracene rings in NiL are observed (Figure $2 b$ ). Besides, the disappearance of proton signals arising from $\mathrm{H}_{1,8,2,7}$ is detected. The abnormal signal pattern is understandable in view of reported X-ray structures of similar $\mathrm{Ni}(\mathrm{II})$ complexes [7]. In the reported structures, anthracene rings are in cis arrangement with intramolecular $\pi-\pi$ stacking. Especially, $\mathrm{H}_{1,8,2,7}$ experience a large coverage by anthracene and thiosemicarbazone fragments, leading to complete broadening of proton signals. Furthermore, due to the coverage by anthracene ring, the imine proton in NiL is markedly upfield 
shifted by 1.44 ppm compared to that in $\mathbf{H L}$ (from $9.27 \mathrm{ppm}$ to $7.83 \mathrm{ppm}$ ).

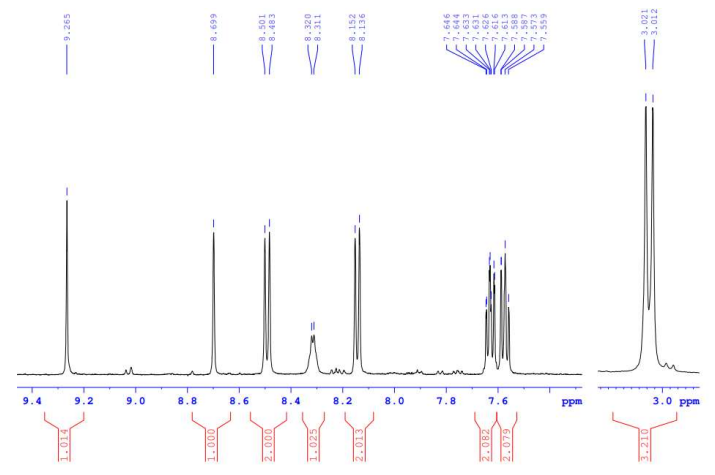

a)

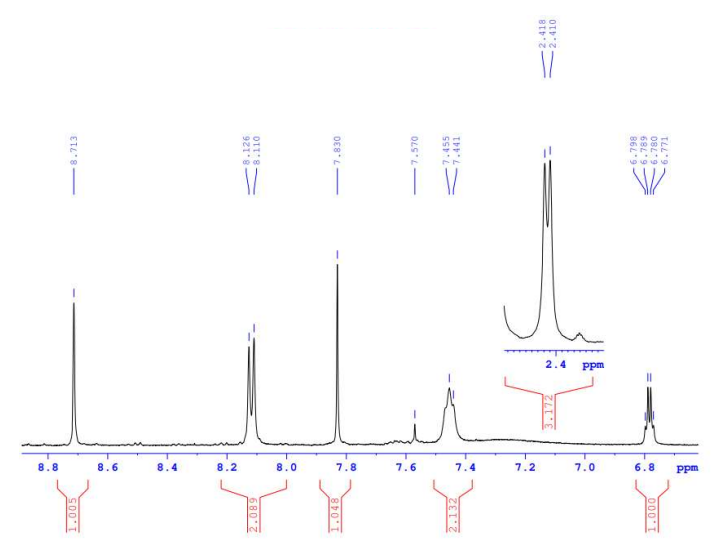

b)

Figure 2: ${ }^{1} \mathrm{H}$ NMR spectrum of a) $\mathbf{H L}$ and b) NiL in DMSO- $d_{6}$.

\subsection{Characterization of $\boldsymbol{H L}$ by X-ray crystallography}

Despite the synthesis of HL was previously reported, no X-ray structure of the ligand was achieved so far. Fortunately, we were able to obtain X-ray quality crystals of HL which allow determination of NiL's molecular structure (Figure 3a). Selected bond lengths and angles of the ligand are given in Table 1. The X-ray structure of HL indicates the presence of 9anthraldehyde and 4-methyl-3thiosemicarbazide moieties, confirming the correct condensation reaction. $\mathrm{C} 1-\mathrm{N} 1$ and
C2-S1 bond distances are of typical values for double bond while $\mathrm{C} 2-\mathrm{N} 2$ bond distance is close to that of a single bond. The bond lengths imply that $\mathbf{H L}$ as the free ligand exists in thione form. All bond angle values $\left(\sim 120^{\circ}\right)$ support $s p^{2}$ hybridization states of $\mathrm{C} 2, \mathrm{~N} 1$ and $\mathrm{N} 2$ atoms in thiosemicarbazone fragment. More importantly, all the atoms of $\mathrm{C}, \mathrm{N}$ and $\mathrm{S}$ in $\mathrm{HL}$ are found to be arranged in the same plane. Consequently, extensive intermolecular $\pi-\pi$ stackings are detected in the solid state of HL (Figure 3b). Nonetheless, the two anthracene rings are not overlapped. Instead, the aromatic ring is substantially covered by a thiosemicarbazone fragment of the adjacent molecule. The parallel separations between the molecules of HL in the stackings are normal (3.316 $\AA$ ).

Table1: Selected bond lengths $(\AA)$ and angles $\left({ }^{\circ}\right)$ of HL.

\begin{tabular}{|l|l|}
\hline \multicolumn{2}{|c|}{ Bond lengths } \\
\hline $\mathrm{S} 1-\mathrm{C} 2$ & $1.685(3)$ \\
\hline $\mathrm{C} 1-\mathrm{N} 1$ & $1.291(5)$ \\
\hline $\mathrm{N} 1-\mathrm{N} 2$ & $1.382(3)$ \\
\hline $\mathrm{N} 2-\mathrm{C} 2$ & $1.345(4)$ \\
\hline $\mathrm{C} 2-\mathrm{N} 4$ & $1.339(4)$ \\
\hline \multicolumn{2}{|c|}{ Bond angles } \\
\hline $\mathrm{C} 1-\mathrm{N} 1-\mathrm{N} 2$ & $113.9(3)$ \\
\hline $\mathrm{N} 1-\mathrm{N} 2-\mathrm{C} 2$ & $121.2(3)$ \\
\hline $\mathrm{N} 2-\mathrm{C} 2-\mathrm{N} 4$ & $116.4(3)$ \\
\hline $\mathrm{N} 2-\mathrm{C} 2-\mathrm{S} 1$ & $120.9(2)$ \\
\hline $\mathrm{N} 4-\mathrm{C} 2-\mathrm{S} 1$ & $122.7(2)$ \\
\hline
\end{tabular}

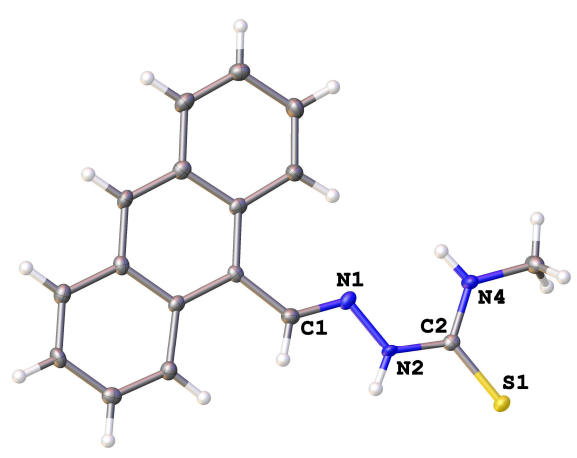

a) 


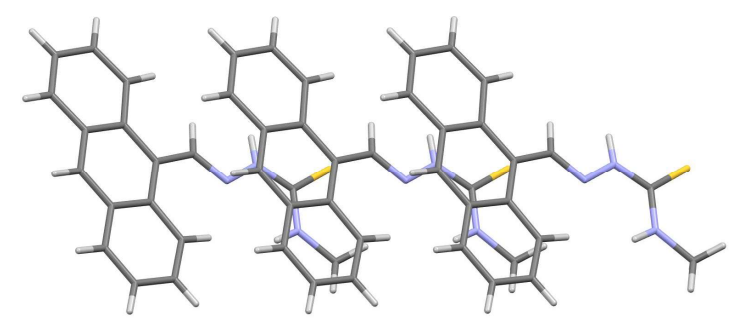

b)

Figure 3: a) X-ray structures of HL; b) Solid-state packing of HL. Color scheme: S, yellow; C, gray; N, blue; $\mathrm{H}$, white.

\subsection{UV-Vis and Photoluminescene Characterizations of $\mathbf{N i L}$}

UV-Vis absorption and emission spectra of $\mathrm{HL}$ and $\mathrm{NiL}$ in $\mathrm{CH}_{2} \mathrm{Cl}_{2}$ are presented in Figure 4 and Figure 5, respectively. The structureless absorption band at $\sim 405 \mathrm{~nm}$ assigned to $\pi \rightarrow \pi^{*}$ transition in NiL is in marked contrast to vibronic absorption band in HL [12]. Also, the complex reveals a severely broad emission band with maximum at $\sim 415 \mathrm{~nm}$ upon excitation at $330 \mathrm{~nm}$. Meanwhile, a well-resolved and characteristic anthracene-based emission band is observed in the spectrum of HL. This might result from the perturbation by $\pi-\pi$ interaction between the two anthracene rings in NiL, as suggested by similar examples $[13,14]$.

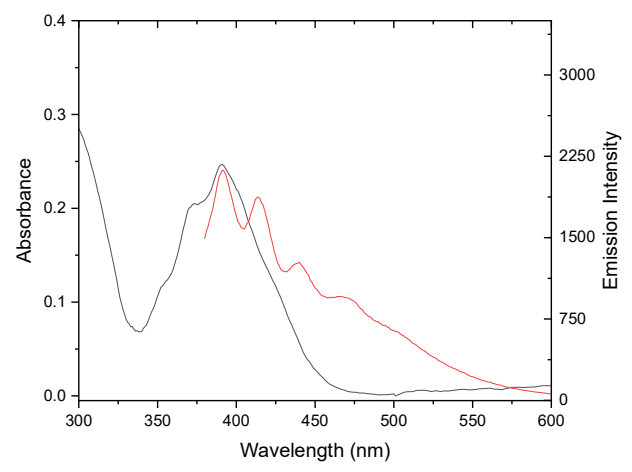

Figure 4: Absorption (black curve) and emission (red curve) spectra of $\mathbf{H L}$ in $\mathrm{CH}_{2} \mathrm{Cl}_{2}$ at room temperature. Excitation wavelength $=330 \mathrm{~nm}$.

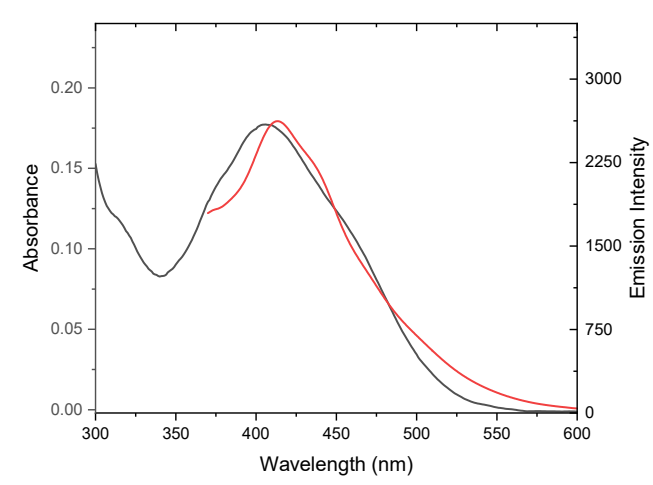

Figure 5: Absorption (black curve) and emission (red curve) spectra of $\mathrm{NiL}$ in $\mathrm{CH}_{2} \mathrm{Cl}_{2}$ at room temperature. Excitation wavelength $=330 \mathrm{~nm}$.

Notably, the Stoke shift in NiL $(\sim 10 \mathrm{~nm})$ is not large enough to be considered as excimer emission which are in the typical range of 450 $550 \mathrm{~nm}$. Therefore, the broadening of emission band at $\sim 415 \mathrm{~nm}$ might be due to steric effect of two closely arranged anthracenyl rings in $\pi-\pi$ stacking. The results are consistent with the disappearance of proton signals in ${ }^{1} \mathrm{H}-\mathrm{NMR}$ spectrum of NiL.

\section{Conclusion}

In summary, we have successfully determined the X-ray structure of $\mathbf{H L}$ and synthesized its $\mathrm{Ni}$ (II) complex. ${ }^{1} \mathrm{H}-\mathrm{NMR}$ spectroscopy showed abnormal signal pattern which is due to intramolecular $\pi-\pi$ stacking between anthracene rings in cis square planar $\mathrm{Ni}$ (II) complex. The unusual molecular structure of NiL was also supported by the broadening of absorption and emission bands.

\section{Acknowledgments}

DAAD is thanked for photoluminescence measurement support through RoHan project. 


\section{References}

[1] M. H. Nguyen, T. N. Nguyen, D. Q. Do, H. H. Nguyen, Q. M. Phung, N. Thirumalaivasan, S. P. $\mathrm{Wu}, \mathrm{T}$. H. Dinh, A Highly Selective Fluorescent Anthracene-Based Chemosensor for Imaging Zn2+ In Living Cells and Zebrafish, Inorg. Chem. Commun., Vol. 115, 2020, 107882. https://doi.org/10.1016/j.inoche.2020.107882.

[2] P. S. Badekar, A. A. Kumbhar, Anthracene-Based Fluorescence Turn on Chemodosimeter for The Recognition of Persulfate Anion, New J. Chem., Vol. 42, 2018, pp. 3917-3923. https://doi.org/10.1039/C7NJ03425C.

[3] J. B. Birks, Excimers, Rep. Prog. Phys., Vol. 38, 1975, pp. 903-974. https://doi.org/10.1088/00344885/38/8/001.

[4] M. P. Heng, S. K. Sinniah, W. Y. Teoh, K. S. Sim, S. W. Ng, Y. K. Cheah, K. W. Tan, Synthesis Of A DNA-Targeting Nickel (II) Complex with Testosterone Thiosemicarbazone Which Exhibits Selective Cytotoxicity Towards Human Prostate Cancer Cells (Lncap), Spectrochim. Acta A, Vol. 150, 2015, pp. 360-372. https://doi.org/10.1016/j.saa.2015.05.095.

[5] V. M. Leovac, S. B. Novaković, G. A. Bogdanović, M. D. Joksović, K. Mészáros Szécsényi, V. I. Češljević, Transition Metal Complexes with Thiosemicarbazide-based ligands. Part LVI: Nickel(II) Complex with 1,3Diphenylpyrazole-4-carboxaldehyde

Thiosemicarbazone and Unusually Deformed Coordination Geometry, Polyhedron, Vol. 26, 2007, pp. 3783-3792.

https://doi.org/10.1016/j.poly.2007.04.012.

[6] M. H. Nguyen, T. T. H. Khuat, H. H. Nguyen, T. H. Dinh, NiII, PdII Complexes with Pyrene-based Thiosemicarbazones: Syntheses, Molecular Structures, and Excimeric Emissions, Z. Anorg. Allg. Chem., Vol. 645, 2019, pp. 113-119. https://doi.org/10.1002/zaac.201800437.

[7] M. H. Nguyen, T. T. H. Khuat, D. Q. Do, H. H. Nguyen, T. H. Dinh, Anthracene-based Ni(II) Thiosemicarbazones with Novel Intramolecular $\pi-$ $\pi$ stackings, Inorg. Chem. Commun., Vol. 118, 2020, 107994. https://doi.org/10.1016/j.inoche.2020.107994.

[8] O. V. Dolomanov, L. J. Bourhis, R. J. Gildea, J. A. K. Howard, H. Puschmann, OLEX2: a Complete Structure Solution, Refinement and Analysis Program, J. Appl. Crystallogr., Vol. 42, 2009, pp. 339-341. https://doi.org/10.1107/S0021889808042726.

[9] G. Sheldrick, SHELXT - Integrated Space Group and Crystal Structure Determination, Acta Cryst. A, Vol. 71, 2015, pp. 3-8. https://doi.org/10.1107/S2053273314026370.

[10] F. A. Beckford, G. Leblanc, J. Thessing, M. Shaloski, B. J. Frost, L. Li, N.P. Seeram, Organometallic Ruthenium Complexes with Thiosemicarbazone Ligands: Synthesis, Structure and Cytotoxicity of [( $76-p-c y m e n e) R u(N S) C l]+$ (NS=9-anthraldehyde thiosemicarbazones), Inorg. Chem. Commun., Vol. 12, 2009, pp. 1094-1098. https://doi.org/10.1016/j.inoche.2009.08.034.

[11] A. N. Kate, A. A. Kumbhar, A. A. Khan, P. V. Joshi, V. G. Puranik, Monitoring Cellular Uptake and Cytotoxicity of Copper(II) Complex Using a Fluorescent Anthracene Thiosemicarbazone Ligand, Bioconjugate Chem., Vol. 25, 2014, pp. 102-114. https://doi.org/10.1021/bc400385d.

[12] M. H. Nguyen, T. T. H. Khuat, H. H. Nguyen, Q. M. Phung, T. H. Dinh, Emissive Pd(II) Thiosemicarbazones Bearing Anthracene: New Complexes with Unusual Coordination Mode, Inorg. Chem. Commun., Vol. 102, 2019, pp. 120125. https://doi.org/10.1016/j.inoche.2019.02.028.

[13] J. Hu, M. H. Nguyen, J. H. K. Yip, Metallacyclophanes of 1,6Bis(diphenylphosphino)pyrene: Excimeric Emission and Effect of Oxygen on Stability of the Rings, Inorg. Chem., Vol. 50, 2011, pp. 74297439. https://doi.org/10.1021/ic102441b.

[14] S.G. Telfer, T.M. McLean, M.R. Waterland, Exciton Coupling in Coordination Compounds, Dalton Trans., Vol. 40, 2011, pp. 3097-3108. https://doi.org/10.1039/C0DT01226B. 